\title{
Reminder treatments do not alleviate cue-to-consequence deficits
}

\author{
TODD R. SCHACHTMAN, WESLEY J. KASPROW, and RALPH R. MILLER \\ State University of New York, Binghamton, New York
}

\begin{abstract}
Using rats in a conditioned lick suppression preparation, six experiments were conducted in which the subjects were exposed to a single tone-LiCl pairing. Despite evidence from tone-shock conditioning that the tone was an adequate conditioned stimulus and evidence from taste-LiCl conditioning that the $\mathrm{LiCl}$ was an adequate unconditioned stimulus, no suppression to the tone was observed following the tone- $\mathrm{LiCl}$ pairing, a finding consistent with prior cue-to-consequence research. In each experiment, subjects receiving a tone- $\mathrm{LiCl}$ pairing were subsequently exposed to either the tone or $\mathrm{LiCl}$ outside the conditioning context in an attempt to reactivate a potentially latent tone- $\mathrm{LiCl}$ association. The parameters of these reminder treatments were chosen on the basis of their previously proven effectiveness in reversing such performance deficits as blocking, overshadowing, latent inhibition, and experimental amnesia. Although a variety of stimulus parameters were used in an effort to reverse the cue-to-consequence deficit, none of the experiments detected any tendency towards suppression by reminded subjects exposed to a tone-LiCl pairing. This uniform lack of reminder-induced recovery suggests that cue-toconsequence deficits reflect true acquisition failure rather than poor retrievability.
\end{abstract}

Garcia and Koelling's (1966) "bright-noisy water" experiment caused a resurgence of interest in Thorndike's (1932) concept of "belongingness." Garcia and Koelling found that in rats an audiovisual cue would more readily act as a conditioned stimulus (CS) for footshock than for toxin, whereas a gustatoryolfactory cue would more readily act as a CS for toxin than for footshock. Using Seligman's (1970) terminology, we shall refer to a readily manifest association as being "prepared" and an association not readily manifest as being "contraprepared." This difference in preparedness, often referred to as the cue-to-consequence effect, does not necessarily prevent all responding based upon contraprepared associations between CSs and unconditioned stimuli (USs); rather, the effect is typically evident in a greater number of CS-US pairings being necessary to achieve behavioral control by contraprepared associations than prepared associations. Moreover, the asymptotic control exerted by contraprepared associations is ordinarily less robust (Seligman, 1970).

Both Garcia and Koelling (1966) and Thorndike (1932) assumed that cue-to-consequence performance deficits were attributable to impaired acquisition. This interpretation has been widely accepted (e.g., Kalat, 1977; Seligman, 1970). However, in recent years several other associative performance

Support for this research was provided by NIMH Grant 33881. Thanks are extended to Stanley R. Scobie, Norman E. Spear, and Joe Serwatka for critically reading an earlier version of this manuscript. Reprint requests may be addressed to Ralph R. Miller, Department of Psychology, SUNY-Binghamton, Binghamton, NY 13901. deficits alleged to arise from acquisition failure have been reinterpreted as reflecting retrieval failure. In each of these instances, after the performance deficit was observed on an initial test, a subsequent test revealed the presence of the target association without further training having occurred between the two test trials. Such recovery of performance has usually been induced by so-called "reminder" treatments that presumably reactivate the target association and enhance its subsequent retrievability. These reminder treatments ordinarily consist of exposure to the CS alone or the US alone, and have proven effective in cases of overshadowing (Kasprow, Cacheiro, Balaz, \& Miller, 1982), blocking (Balaz, Gutsin, Cacheiro, \& Miller, 1982), latent inhibition (Kasprow, Catterson, Schachtman, \& Miller, in press), and experimental amnesia (Deweer, Sara, \& Hars, 1980; Miller \& Springer, 1972), to mention but a few. Such recovery of performance suggests that cue-to-consequence performance deficits may similarly arise in part or entirely from retrieval failure rather than acquisition failure. This position is supported by evidence that audiovisual-toxin associations which fail to produce avoidance of the audiovisual cues will be manifest when assessed by indirect means such as sensory preconditioning (Archer \& Sjödén, 1982), transfer tests (Riccio \& Haroutunian, 1977), potentiation (Morrison \& Collyer, 1974), and blocking (Krane, 1980). Alternatively, these indirect indices may yield positive results, not because they tap difficult-to-retrieve associations, but because they are more sensitive to the weak, but readily retrievable, audiovisual-toxin associations that are widely acknowledged to occur. 
The present experiments attempted to obtain direct evidence of latent tone-toxin associations through the use of a pretest reminder treatment. Because prepared associations are readily manifest after a single conditioning trial, whereas contraprepared associations become evident slowly over numerous trials, the largest difference between prepared and contraprepared associations is seen following a single CSUS pairing. Accordingly, the present research employed a single conditioning trial so as to have the largest possible range between prepared and contraprepared associations in which to see some consequence of reminder treatments. Alternatively stated, repeated pairings of contraprepared stimuli ordinarily produce a degree of manifest conditioning. However, if the only difference between prepared and contraprepared associations is the degree of manifestation, then the strong, prepared associations manifest after a single pairing of prepared stimuli should correspond to equally strong, latent associations between contraprepared stimuli after a single pairing. With repeated pairings, more of the contraprepared association would be manifest; hence, there would be less room for a potential difference in test performance with and without a preceding reminder treatment.

The tone used in each of the present studies has been repeatedly found, in various suppression tasks using rats in our laboratory, to serve as an effective CS after being paired once with footshock, even relatively weak footshock (e.g., Balaz, Kasprow, \& Miller, 1982). Because of the well-established ability of the tone to serve as a CS, no further effort was made to demonstrate this in the present research. In each experiment, three groups of rats received a single tone- $\mathrm{LiCl}$ pairing. During the retention interval, one group received a tone reminder (TR) and a second group received a $\mathrm{LiCl}$ reminder (LR). The third group received no reminder (NR) and served as a baseline for departure by Groups TR and LR. For purposes of comparison, a fourth group received a single sucrose-LiCl pairing (S). Group $\mathrm{S}$ was included to demonstrate the effectiveness of the $\mathrm{LiCl}$ as a US and roughly estimate the magnitude of suppression that might be expected from the reminded animals. Finally, to establish a nonassociative baseline for lick suppression to the tone, a fifth group, included only in Experiments 1 and 6 received the tone and $\mathrm{LiCl}$ explicitly unpaired (EU). The individual studies investigated various conditioning and reminder parameters. Generally speaking, the training and reminder parameters were selected to be analogous to prior studies in which reminder treatments had proven effective in reversing a variety of performance deficits. Throughout the series, lick suppression in the presence of the CS and fluid volume consumed during the test session were the measures of associative strength.

\section{EXPERIMENT 1}

In the first experiment, Groups NR, TR, and LR were exposed to a tone that was initiated $30 \mathrm{sec}$ prior to a $\mathbf{~} \mathrm{iCl}$ injection and continued for $\mathbf{3 0} \mathrm{min}$ following the injection, during which time the injected subjects were demonstrably sick as judged by their postures and defecation. Group $S$ was presented with a sucrose solution rather than the tone for $30 \mathrm{sec}$ prior to, and for $30 \mathrm{~min}$ following, the injection. Group EU received the 30.5-min tone exposure and $2 \mathrm{~h}$ later was injected with $\mathrm{LiCl}$. Reminder treatments consisted of a single $\mathrm{LiCl}$ injection for Group LR and a $30-\mathrm{sec}$ exposure to the tone for Group TR. In order to prevent potential confounding by associations to the context that might develop during the reminder treatment, both reminder treatments occurred outside the apparatus used for conditioning and testing. All subjects were tested concomitantly on the sucrose solution and the tone; response measures of lick latency and volume consumed were recorded.

\section{Method}

Subjects. Twenty-four male naive Sprague-Dawley rats from a commercial breeding company (Holtzman, Madison, WI) served as subjects. The animals were approximately 57 days old and ranged in weight from 170 to $213 \mathrm{~g}$. The subjects were individually housed in standard wire mesh cages with free access to Purina Lab Chow in a vivarium maintained on a 16-8-h light/dark cycle. The experiment was conducted during the light portion of this cycle. All rats were exposed to a graded deprivation schedule prior to Day 1 that culminated in $10 \mathrm{~min}$ of access to water per day; this schedule was maintained throughout the experiment. Experimental manipulations were initiated each day 18-22 h after the water bottles had been removed the previous day. All subjects were handled for approximately $30 \mathrm{sec}$ daily for 1 week prior to the beginning of the study:

Apparatus. The conditioning apparatus consisted of 12 chambers, measuring $24.1 \times 12.7 \times 20 \mathrm{~cm}(1 \times \mathrm{w} \times \mathrm{h})$, housed in individual sound-attenuating environmental enclosures. The chambers were constructed of Plexiglas with three opaque walls and a transparent front wall and ceiling. Each chamber was dimly illuminated by a 1.12-W (No. 1820) bulb located between the environmental enclosure and a side wall of the chamber. The floor consisted of narrow stainless steel rods electrically shorted together. A lick tube was inserted through a $1.5-\mathrm{cm}$-wide horizontal slit in an opaque wall of the chamber. The end of the lick tube was located $2.5 \mathrm{~cm}$ above the floor. An electronic contact circuit between the lick tube and floor was used to monitor licking. Mounted on the ceiling of each chamber was a 45-요 speaker that was used for presentation of the auditory CS, a 1300-Hz tone $10 \mathrm{dBC}$ (re $20 \mu \mathrm{N} / \mathrm{m}^{2}$ ) above an $80-\mathrm{dBC}$ background noise produced by fans mounted on a side of the environmental enclosure. An $8 \%(w / v)$ sucrose solution served as the CS for Group S. A 10 -cc syringe with a $25-\mathrm{ga} 1.59-\mathrm{cm}$ hypodermic needle was used to inject $1.33 \%$ body weight of $.3-\mathrm{M} \mathrm{LiCl}$. A $78-\mathrm{dBC}$ ambient white noise was present in the room housing the conditioning chambers during all phases of the experiment.

Tone reminder treatments were administered in a truncated $\mathrm{V}$ shaped enclosure that was $41.6 \mathrm{~cm}$ long, $5 \mathrm{~cm}$ wide at the base, $20.7 \mathrm{~cm}$ wide at the top, and $28.3 \mathrm{~cm}$ in height. The sloping side walls were stainless steel, the floor of the enclosure consisted of two 2-cm-wide stainless steel parallel plates separated by a $1-\mathrm{cm}$ gap, and the roof and end walls were of black Plexiglas. The re- 
minder enclosure was dimly illuminated by a $7-\mathrm{W}$ white light bulb located outside the apparatus. A $45-\Omega$ speaker positioned outside the apparatus allowed the presentation of a $1300-\mathrm{Hz}$ tone highly similar to that used in conditioning.

$\mathrm{LiCl}$ reminder treatments consisted of placing the subjects, after the reminder injection, in a holding cage measuring $23 \times 15.1 \times$ $17.7 \mathrm{~cm}(1 \times \mathrm{w} \times \mathrm{h})$ with three wooden side walls and a wire mesh front wall. The chamber had a sheet metal ceiling and floor, with the latter layered with shredded newsprint. All reminder manipulations were conducted in a room distinctly dissimilar from that housing the conditioning chambers.

Procedure. Each subject was acclimated to a conditioning chamber and trained to lick water from the lick tube in that chamber on Days 1-8. The extensive preexposure to the chambers was intended to minimize associations between the context and the US during conditioning, thereby reducing the likelihood of contextual cues overshadowing the tone. On Day 1 , the lick tubes protruded approximately $1 \mathrm{~cm}$ into each chamber. On Days 3, 4, and 8 , the lick tubes were flush with the wall of the chambers. On Days 2, 5, 6, and 7, the lick tubes were absent from the chambers. Latencies in seconds to complete the first and second 250 licks on Days $1,3,4$, and 8 were recorded as an index of both adaptation to the training enclosures and baseline lick rates. As there were no appreciable differences in lick latencies between subjects on Day 8 , the animals were assigned randomly, except for counterbalancing of body weight, to one of five treatment conditions. Additionally, on Day 8 the rats were weighed in order to determine the quantity of $\mathrm{LiCl}$ to be injected on Day 9.

Conditioning was conducted on Day 9. The lick tubes contained the sucrose solution for subjects in Group $S(n=4)$ and water for animals in Groups TR $(n=4), \operatorname{LR}(n=4), N R(n=4)$, and EU $(n=8)$. Group EU was not included in Experiments 2-5. Rather, implicit cross-experiment comparisons were made to this group in subsequent experiments. For this reason, we attempted to minimize the variance in Group EU in Experiment 1 by assigning to it a relatively large number of animals. All subjects were placed into their conditioning chambers for $2 \mathrm{~min}$ with the lick tubes initially absent. Following this interval, water-filled lick tubes were placed into the chambers and the tone was presented to Groups TR, LR, EU, and NR. Group S was presented with lick tubes filled

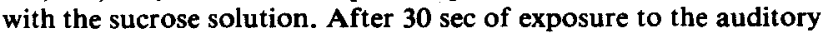
or gustatory CS (during which time all subjects were observed to drink), the subjects in Groups $S, L R, T R$, and NR were removed from the conditioning chambers, administered an ip injection of $\mathrm{LiCl}$, and then returned to their chambers for another $30 \mathrm{~min}$. Animals in Group EU were removed and immediately replaced into the conditioning chamber without an injection. The tone and sucrose cues remained present in the respective conditioning chambers during this time. Following this 30 -min period, the subjects were returned to the home cage. At this time, $\mathrm{LiCl}$-exposed subjects were examined for evidence of $\mathrm{LiCl}$-induced illness. Subjects in Group EU remained in the home cage for $120 \mathrm{~min}$ and were then returned to the conditioning chamber. Following a 30-sec interval, they were removed and administered a $\mathrm{LiCl}$ injection.
The subjects were then replaced into the chamber with the lick tube present but without exposure to the tone for $30 \mathrm{~min}$ before being returned to their home cages.

All subjects remained in their home cages on Day 10 to permit recovery from the LiCl-induced illness. On Day 11, Groups LR and TR were administered reminder treatments. Animals in Group LR were given an ip injection of $\mathrm{LiCl}$ identical to that used in conditioning. Following the reminder injection, subjects in Group LR were placed into the novel holding cage for $120 \mathrm{~min}$ and subsequently returned to the home cage. Animals in Group TR were placed in the CS-reminder enclosure for a 4.5-min session, during the middle $30 \mathrm{sec}$ of which the tone was presented. Animals in Groups S, EU, and NR remained undisturbed in their home cages on Day 11.

In order to allow rats in Group $\mathrm{LR}$ to recover from the $\mathrm{LiCl}$ reminder treatment, there were no experimental manipulations conducted on Day 12. Testing occurred on Day 13. Each subject was placed in its conditioning chamber with the lick tube filled with the $8 \%$ sucrose solution. Upon completion of 250 licks, the tone was initiated and remained present until the subject either completed an additional 250 licks or suppressed for $1,800 \mathrm{sec}$. This procedure guaranteed that all subjects were licking at the time of tone onset. Similarly all subjects were necessarily licking at the time of initial sucrose presentation. The asymmetry between sucrose testing and tone testing, that is, the initiation of the sucrose test at Lick 1 and of the tone test at Lick 250 is considered in the Discussion of Experiment 1 and is explicitly controlled for in Experiment 6 along with possible problems arising from stimulus generalization decrement. Latencies to complete the first and second 250 licks were recorded. In addition, the amount of sucrose solution consumed during the test session was recorded for all subjects. Each animal remained in the chambers for $\mathbf{3 0} \mathrm{min}$ and was then returned to its home cage.

\section{Results and Discussion}

Latencies to complete the first and second 250 licks on Days 8 and 13 were transformed to log latencies (base 10) to permit the use of parametric statistics. The criterion for rejection of the null hypothesis was set at $\mathrm{p}<.05$ for all statistical tests. Mean latency values as well as mean volumes consumed on Days 8 and 13 are presented in Table 1 . Analyses of variance (ANOVAs) for unequal sample size found no betweengroup differences in mean volumes of water consumed and latencies to complete the first or second 250 licks on the last pretraining day, Day 8 (Fs $<1$ ).

On Day 13, no subject reached the 1,800-sec ceiling value during the test. It should be noted that the test procedure for tone-trained animals and sucrose-trained animals was potentially confounded in that the crit-

Table 1

Mean Lick Training and Test Suppression Data From Experiment 1

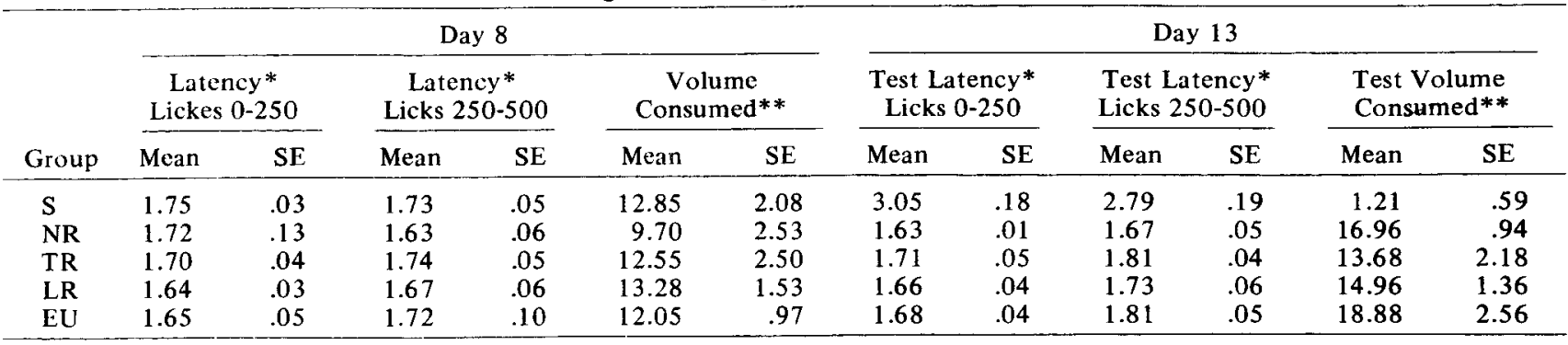

*In log sec \pm standard error.

**In $m l \pm$ standard error.


ical stimulus for Group S (sucrose) was present during the entire test, whereas the critical stimulus (tone) for Groups NR, TR, LR, and EU was present only during Licks $250-500$. Thus, only during the second 250 licks were the critical and noncritical stimuli present for all animals. Consequently, the second 250 licks served as a more valid response measure and was used in all statistical analyses of suppression latencies in this experiment. All test latencies, however, are available in Table 1 . It should be noted that the tone was not presented at the beginning of the test trial because the subjects would then have received the tone prior to the initiation of licking; moreover, prior unpublished research in our laboratory has found that presenting the tone contingent on the first lick of the test session increases variance in lick suppression independent of prior experience with the tone. The present delayed onset of the tone during testing could have allowed a decrease in thirst and consequently was a potential bias towards conditioned lick suppression to the tone relative to the sucrose. (This issue is empirically addressed in Experiment 6). Moreover, the lack of import concerning the use of the latency of the first or second 250 licks by Group S is evident in the high similarity of these two measures (see Table 1).

An ANOVA conducted on Day $13 \log$ latencies to complete Licks $250-500$ yielded a significant treatment effect $\left[F(4,18)=33.27, \mathrm{MSe}=.03 \mathrm{log} \mathrm{sec}^{2}\right.$, $\mathrm{p}<.001]$. An ANOVA conducted on volumes of sucrose solution consumed during the test session also revealed treatment differences $[F(4,19)=8.83$, MSe $=$ $24.34 \mathrm{ml}^{2}, \mathrm{p}<.001$ ]. Planned comparisons of group means for volume and latency measures found no effect of either reminder treatment [LR vs. NR volumes and latencies, Fs $<1$; TR vs. NR latencies, $F(1,19)=1.52, p>.10 ;$ TR vs. NR volumes, $F<1]$. However, the sucrose-LiCl group differed significantly from all the tone-LiCl trained groups [S vs. NR latencies, $F(1,19)=97.32 ; S$ vs. $N R$ volumes, $F(1,19)=22.65 ; S$ vs. $L R$ latencies, $F(1,19)=83.92$; $S$ vs. $L R$ volumes, $F(1,19)=17.26 ; S$ vs. TR latencies, $F(1,19)=74.51$; $S$ vs. TR volumes, $F(1,19)=14.20$ ] The suppression of licking seen in Group $S$ testifies to the effectiveness of the $\mathrm{LiCl}$ as a US. Finally, the group that received the tone and $\mathrm{LiCl}$ explicitly unpaired on Day 9 did not differ from Group NR [NR vs. EU latencies, $F(1,19)=1.52, p>.10 ; N R$ vs. EU volumes, $F<1]$. This last observation suggests that the tone- $\mathrm{LiCl}$ performance deficit was complete. Note that group mean suppression latencies and volumes on the test day (Day 13) are comparable to those on the final day of lick training (Day 8) in each of the tone-trained groups. This supports the conclusion that no suppression was manifest by either the reminded or the nonreminded tone- $\mathrm{LiCl}$ groups. Assessment of conditioned suppression was confined to the analysis of differences between groups on Day 13.
A within-subject comparison between Day 8 and Day 13 measures could not be unambiguously interpreted since different solutions were present on these sessions.

The results are consistent with the well-established cue-to-consequence deficit, that is, a single sucrose$\mathrm{LiCl}$ pairing produced robust avoidance whereas a single tone-LiCl pairing did not. Moreover, both reminder manipulations were ineffectual in attenuating this deficit. Assuming the adequacy of the reminder treatments, the lack of effect of the reminder treatment might reflect an absence of retrieval failure underlying cue-to-consequence effects. There are, however, several other possible interpretations of the results. The following experiments were each designed to address one or another of these alternatives. For example, subjects may have adapted to the tone during the $30-\mathrm{sec}$ preinjection and 30 -min postinjection exposures on the conditioning trial. Such adaptation could have interfered with acquisition and/or test-trial processing necessary for suppression. Experiment 2 sought to prevent habituation through the use of an intermittent tone.

\section{EXPERIMENT 2}

The possibility that adaptation to the continuous tone used in Experiment 1 had interfered with either acquisition or conditioned responding to the tone prompted us to employ a pulsing tone as the CS in Experiment 2. Presumably a pulsating tone would better sustain attention and result in less adaptation per unit exposure time than a continuous tone.

\section{Method}

Twenty-four naive male rats approximately 60 days of age were used as subjects. The animals weighed $160-255 \mathrm{~g}$; the source and maintenance of the rats were the same as those in Experiment 1.

The apparatus and procedure were identical to Experiment 1 except that a 10-dBC (above background) $1300-\mathrm{Hz}$ pulsing tone was employed as the CS for Groups NR, TR, and LR on Days 9 and 13. Specifically, the tone consisted of pulses, $.95 \mathrm{sec}$ in duration, separated by $.05 \mathrm{sec}$. Additionally, the pulses were emitted on a $90 \%$ probability schedule; on the average, nine tone pulses occurred during each 10-sec interval. The pulsing tone was also presented as a reminder to Group TR on Day 11, using the same procedure as in Experiment 1. A group that received the tone and $\mathrm{LiCl}$ explicitly unpaired was not included in Experiment 2. Group $S$ was treated as it had been in Experiment 1. Six subjects were assigned randomly to each of the four groups.

\section{Results and Discussion}

One subject each from Groups NR and TR and two subjects from Group LR were eliminated from the study due to procedural errors. Latencies from the last day of lick training (Day 8) and the test day (Day 13) for the remaining animals were transformed to log latencies. Mean suppression and consumption scores from the last day of lick training (Day 8) and the test day (Day 13) are presented in Table 2. No differences between groups in log latencies for Licks 
Table 2

Mean Lick Training and Test Suppression Data From Experiment 2

\begin{tabular}{|c|c|c|c|c|c|c|c|c|c|c|c|c|}
\hline Group & \multicolumn{6}{|c|}{ Day 8} & \multicolumn{6}{|c|}{ Day 13} \\
\hline $\begin{array}{l}\text { S } \\
\text { NR } \\
\text { TR } \\
\text { LR }\end{array}$ & $\begin{array}{l}1.72 \\
1.67 \\
1.68 \\
1.71\end{array}$ & $\begin{array}{l}.06 \\
.02 \\
.03 \\
.05\end{array}$ & $\begin{array}{l}1.68 \\
1.70 \\
1.67 \\
1.68\end{array}$ & $\begin{array}{l}.05 \\
.02 \\
.03 \\
.03\end{array}$ & $\begin{array}{l}14.63 \\
13.91 \\
14.93 \\
15.11\end{array}$ & $\begin{array}{r}.92 \\
1.28 \\
1.32 \\
.97\end{array}$ & $\begin{array}{l}2.68 \\
1.71 \\
1.80 \\
1.71\end{array}$ & $\begin{array}{l}.10 \\
.08 \\
.09 \\
.13\end{array}$ & $\begin{array}{l}2.66 \\
1.75 \\
1.79 \\
1.75\end{array}$ & $\begin{array}{l}.13 \\
.09 \\
.11 \\
.14\end{array}$ & $\begin{array}{r}2.29 \\
18.12 \\
15.62 \\
19.24\end{array}$ & $\begin{array}{r}.36 \\
1.49 \\
1.61 \\
3.62\end{array}$ \\
\hline
\end{tabular}

*In log sec \pm standard error. $\quad$ **In $\mathrm{ml} \pm$ standard error.

0-250, Licks 250-500, or in volumes consumed were observed on Day 8 (Fs $<1)$. ANOVAs conducted on test latencies and volumes (Day 13) of sucrose solution consumed yielded significant between-group mean differences [latencies for Licks $250-500, F(3,16)$ $=14.04, \mathrm{MSe}=.07 \log \mathrm{sec}^{2}$; volumes, $\mathrm{F}(3,16)=$ 18.71, $\mathrm{MSe}=16.06 \mathrm{ml}^{2}$ ]. Planned comparisons on group means found no reminder effect for either response measure [LR vs. NR, Fs $<1$; TR vs. NR, Fs $<1$ l, and again Group $S$ manifested significantly more suppression than the other groups [S vs. LR latencies for Licks $250-500, F(1,16)=28.97$; $S$ vs. $L R$ volumes, $F(1,16)=43.81$; $S$ vs. TR latencies, $F(1,16)$ $=26.48 ; S$ vs. TR volumes, $F(1,16)=27.09$; $S$ vs. NR latencies, $F(1,16)=28.97 ; S$ vs. $N R$ volumes, $F(1,16)$ $=38.26$. These results suggest that intratrial $C S$ adaptation was not likely the primary cause of poor manifest conditioning to the tone in Experiment 1.

\section{EXPERIMENT 3}

The next experiment used a 5-min interval between $\mathrm{CS}$ onset and $\mathrm{LiCl}$ injection rather than the 30-sec interval that was used in Experiments 1 and 2. This modification of the CS-US temporal relationship was predicated on the possibility that the optimal CS$\mathrm{LiCl}$ interval for conditioning was longer than $30 \mathrm{sec}$. Use of this longer interval sought to enhance the potential of the CS as a predictor of the subsequent illness.

\begin{abstract}
Method
Twenty-four male naive rats, approximately 80 days old and weighing $280-365 \mathrm{~g}$, were used as subjects. The source and maintenance of the rats were the same as in the previous experiments. The procedure was identical to Experiment 2 except that subjects were exposed to their respective CS (pulsing tone or sucrose) for 5 min prior to $\mathrm{LiCl}$ administration on the conditioning day. Following the injection, the rats remained in the conditioning enclosure with the $C S$ present for $30 \mathrm{~min}$ and were then returned to the home cage. Six animals were included in each group.
\end{abstract}

\section{Results and Discussion}

Mean $\log$ latencies and consumption measures during the final day of lick training (Day 8) and the test day (Day 13) are depicted in Table 3. Separate ANOVAs of Day $8 \mathrm{log}$ latencies (Fs $<1$ ), and vol- umes consumed $[F(3,19)=1.31, p>0.25]$ revealed no between-group mean differences. ANOVAs of Day 13 scores found significant differences between group means [latencies, $\mathrm{F}(3,20)=131.33 ; \mathrm{MSe}=\mathbf{0 . 0 1}$ $\log \mathrm{sec}^{2}$; volumes, $\mathrm{F}(3,20)=71.31, \mathrm{MSe}=5.55 \mathrm{ml}^{2}$ ]. Planned comparisons detected no reminder effect [NR vs. TR latencies, $F(1,20)=3.46, p>.05 ; N R$ vs. TR volumes, $F(1,20)=3.54, p>.05 ; \mathrm{NR}$ vs. $L R$ latencies and volumes, Fs $<1]$, but Group $S$ differed from the subjects trained with the tone [S vs. NR latencies, $F(1,20)=274.78$; $S$ vs. NR volumes, $F(1,20)$ $=151.10 ; S$ vs. TR latencies, $F(1,20)=216.20 ; S$ vs. TR volumes, $F(1,20)=108.37$; $S$ vs. $L R$ latencies, $F(1,20)=290.40$; $S$ vs. $L R$ volumes, $F(1,20)=159.90$ ]. Hence, a 5-min interval between CS onset and US onset during the single training trial yielded no enhancement of manifest suppression in Groups NR, $L R$, or TR relative to a $30-\sec$ interval.

\section{EXPERIMENT 4}

Experiment 4 sought to obtain suppression to the tone in groups exposed to a tone-LiÇl pairing, by increasing the saliency of the tone. Specifically, the intensity of the tone was increased to $15 \mathrm{dBC}$ above background from the 10-dBC difference employed in Experiments 1-3.

\section{Method \\ Twenty-four naive male rats were used as subjects. The animals were approximately 90 days old and ranged in weight from 220 to $300 \mathrm{~g}$. The source and maintenance of the rats were the same as in the previous experiments. The apparatus and procedures used were identical to those of Experiment 2, that is, a 30-sec CS- onset to US-onset interval, with the exception that the intensity of the pulsing tone was increased to $15 \mathrm{dBC}\left(\mathrm{re} .20 \mu \mathrm{N} / \mathrm{m}^{2}\right.$ ) above the 80 -dBC background noise. There were six animals in each of four groups.}

\section{Results and Discussion}

Three animals, one from each of Groups S, TR, and NR, were eliminated due to procedural errors. The volume and latency data from Days 8 and 13 are illustrated in Table 4. ANOVAs conducted on the data from Day 8 detected no between-group differences for Licks 0-250 (F < 1), Licks 250-500 [F(3,17) $=2.18, \mathrm{p}>.10]$, or volumes $[\mathrm{F}(3,17)=1.31, \mathrm{p}>.25]$. 
Table 3

Mean Lick Training and Test Suppression Data From Experiment 3

\begin{tabular}{|c|c|c|c|c|c|c|c|c|c|c|c|c|}
\hline Group & \multicolumn{6}{|c|}{ Day 8} & \multicolumn{6}{|c|}{ Day 13} \\
\hline $\mathbf{S}$ & 1.63 & .05 & 1.63 & .06 & 19.37 & 1.44 & 2.72 & .09 & 2.74 & .07 & 1.52 & .64 \\
\hline NR & 1.59 & .05 & 1.62 & .06 & 21.55 & 1.50 & 1.66 & .04 & 1.67 & .04 & 18.24 & .88 \\
\hline TR & 1.60 & .04 & 1.64 & .06 & 17.20 & 1.80 & 1.66 & .05 & 1.79 & .03 & 15.68 & 1.37 \\
\hline
\end{tabular}

*In log sec \pm standard error. $\quad * * I n m l \pm$ standard error.

Table 4

Mean Lick Training and Test Suppression Data From Experiment 4

\begin{tabular}{|c|c|c|c|c|c|c|c|c|c|c|c|c|}
\hline \multirow{2}{*}{ Group } & \multicolumn{6}{|c|}{ Day 8} & \multicolumn{6}{|c|}{ Day 13} \\
\hline & \multicolumn{2}{|c|}{$\begin{array}{c}\text { Latency* } \\
\text { Licks } 0-250\end{array}$} & \multicolumn{2}{|c|}{$\begin{array}{c}\text { Latency* } \\
\text { Licks } 250-500 \\
\end{array}$} & \multicolumn{2}{|c|}{$\begin{array}{c}\text { Volume } \\
\text { Consumed } * *\end{array}$} & \multicolumn{2}{|c|}{$\begin{array}{c}\text { Test Latency* } \\
\text { Licks 0-250 }\end{array}$} & \multicolumn{2}{|c|}{$\begin{array}{l}\text { Test Latency* } \\
\text { Licks 250-500 } \\
\end{array}$} & \multicolumn{2}{|c|}{$\begin{array}{l}\text { Test Volume } \\
\text { Consumed** }\end{array}$} \\
\hline $\mathrm{S}$ & 1.71 & .09 & 1.79 & .06 & 14.60 & .78 & 2.67 & .26 & 2.61 & .23 & 5.80 & 2.60 \\
\hline NR & 1.62 & .04 & 1.65 & .05 & 16.42 & 1.32 & 1.66 & .03 & 1.79 & .02 & 20.20 & 1.31 \\
\hline TR & 1.67 & .04 & 1.70 & .06 & 14.50 & 1.91 & 1.79 & .14 & 1.89 & .15 & 16.10 & .69 \\
\hline
\end{tabular}

*In log sec \pm standard error. $\quad$ **In $m l \pm$ standard error.

ANOVAs of the Day 13 data found significant differences between groups for latencies $[F(3,17)=7.37$, $\left.\mathrm{MSe}=.11 \log \sec ^{2}, \mathrm{p}<.01\right]$ and volumes $[\mathrm{F}(3,17)=$ 13.37, $\left.\mathrm{MSe}=15.12 \mathrm{ml}^{2}, \mathrm{p}<.001\right]$. Consistent with the pattern of results obtained in Experiments 1-3, planned comparisons revealed no reminder effect of either tone or $\mathrm{LiCl}$ [NR vs. TR latencies, $\mathrm{F}<1$; NR vs. TR volumes, $F(1,17)=2.96, p>.10 ; N R$ vs. $L R$ latencies, $F<1$; $N R$ vs. $L R$ volumes, $F(1,17)=2.20$, $\mathrm{p}>.10]$. Suppression was again greater by Group $S$ than by all the tone-LiCl trained groups [S vs. NR latencies, $F(1,17)=16.03 ; S$ vs. $N R$ volumes, $F(1,17)$ $=36.12$; $S$ vs. $L R$ latencies, $F(1,17)=12.36$; $S$ vs. LR volumes, $F(1,17)=20.50 ; S$ vs. TR latencies, $F(1,17)=12.36$; $S$ vs. $T R$ volumes, $F(1,17)=20.50$ ]. These results indicate that the greater salience of the tone achieved by increasing the intensity of the tone had little or no effect on manifest suppression by tone-trained animals.

\section{EXPERIMENT 5}

A procedural discrepancy between sucrose- $\mathrm{LiCl}$ and tone- $\mathrm{LiCl}$ training in Experiments 1-4 was that the sucrose cue exposures in those experiments were dependent on licking whereas tone exposures were not. This distinction may have contributed to the lack of manifest conditioning to the tone observed in Experiments 1-4. In Experiment 5, tone presentation during training and testing was contingent upon subjects' licking from the lick tube. In all other respects, the study was identical to Experiment 1 . Be- cause the reminder session was conducted with the lick tubes absent, the CS reminder for Group TR consisted of a 30 -sec tone presentation that closely approximated the intermittent quality of the training tone that resulted from its dependency upon licking on Day 9.

\section{Method}

Nine male and nine female naive Sprague-Dawley-descended rats, approximately 65 days of age and ranging in weight from 199 to $240 \mathrm{~g}$, were used as subjects. The rats were bred in our laboratory and were maintained as in the previous experiments. All groups were counterbalanced for body weight and sex. The procedure deviated from that of Experiment 1 only in that tone onset at training on Day 9 for Groups TR $(n=5)$, NR $(n=5)$, and LR $(n=4)$ occurred when subjects licked from the water tube and the tone terminated each time the animals ceased licking. Group $S(n=4)$ was trained as in Experiments $1-4$. $\mathrm{LiCl}$ administration for all subjects on Day 9 occurred $30 \mathrm{sec}$ following each animal's initial contact with the lick tube (and consequently the CS). The reminder treatment for Group TR consisted of presentation of a tone that was highly similar to the lick-contingent tone actually experienced during training. Specifically, 2 min into the 4.5-min reminder session, the following sequence was initiated: 4-sec tone, 2-sec silence, 12-sec tone, 2-sec silence, and a 10-sec tone. During testing on Day 13, the tone presentation for all subjects was contingent on contact with the lick tube for all that remained of the 30-min session after completion of an initial 250 licks, rather than merely during the interval necessary to complete Licks 250-500 as in Experiments 1-4.

\section{Results and Discussion}

Group mean sucrose consumption and $\log$ latencies to Lick 250 and to Lick 500 on Days 8 and 13 are presented in Table 5. No effect of sex was observed on either response measure or in any interac- 
Table 5

Mean Lick Training and Test Suppression Data From Experiment 5

\begin{tabular}{|c|c|c|c|c|c|c|c|c|c|c|c|c|}
\hline Group & \multicolumn{6}{|c|}{ Day 8} & \multicolumn{6}{|c|}{ Day 13} \\
\hline S & 1.86 & .04 & 1.84 & .08 & 15.01 & 1.48 & 3.43 & .09 & 2.70 & .28 & 4.30 & 1.60 \\
\hline NR & 1.73 & .09 & 1.69 & .04 & 17.10 & 1.63 & 1.75 & .05 & 1.78 & .06 & 25.70 & 1.40 \\
\hline TR & 1.89 & .13 & 1.78 & .07 & 13.49 & 1.81 & 1.74 & .05 & 1.77 & .09 & 23.00 & 1.50 \\
\hline
\end{tabular}

*In log sec \pm standard error. $\quad * *$ In $m l \pm$ standard error.

tion with treatment; hence, treatments were collapsed across sexes. No between-group differences were obtained for responses on Day 8 [volumes and latencies for Licks 0-250, Fs $<1$, and Licks 250-500, $F(3,11)$ $=1.45, \mathrm{p}>.25]$. The latencies to complete Licks 250 500 for two subjects in Group S were not available on Day 13 because these subjects did not complete Licks 0-250. ANOVAs on latency and volume measures from Day 13 found significant differences between groups [latencies for Licks 250-500, $F(3,11)$ $=20.47, \mathrm{MSe}=0.034 \mathrm{log} \mathrm{sec}^{2}$; volumes, $\mathrm{F}(3,13)=$ 26.24, $\mathrm{MSe}=15.26 \mathrm{ml}^{2}$; both ps $<.001$ ]. Planned comparisons between means revealed no reminder effect [NR vs. TR latencies and volumes, both Fs $<1$; NR vs. $L R$ latencies, $F<1$; NR vs. $L R$ volumes, $F(1,13)=1.89, p>.10]$. However, significant differences between Group $S$ and each of the tone-trained groups were found [S vs. NR latencies, $F(1,11)=$ 42.08; $S$ vs. NR volumes, $F(1,13)=62.95$, $S$ vs. TR latencies, $F(1,11)=43.00$; $S$ vs. TR volumes, $F(1,13)$ $=48.45$; $S$ vs. $L R$ latencies, $F(1,11)=37.63$; $S$ vs. LR volumes, $F(1,13)=43.03$; all ps $<.001]$. Notably, the consumption measure in this experiment was probably more sensitive than in the previous studies because the tone was present for the entire test session after Lick 250 (provided the subject was licking) rather than only during the interval between Licks 250 and 500 . In summary, it appears that the discrepancy between lick-contingent and noncontingent CS exposure in Experiments 1-4 was not the primary source of differences in suppression following a sucrose- $\mathrm{LiCl}$ and tone- $\mathrm{LiCl}$ pairing.

\section{EXPERIMENT 6}

In Experiments 1-5, all subjects were tested with the tone and sucrose present. As conditioning consisted of pairing $\mathrm{LiCl}$ with only tone or sucrose, the presence of both tone and sucrose during testing may have resulted in stimulus generalization decrement between conditioning and testing. Moreover, if the sucrose was more salient than the tone, stimulus generalization decrement would have been more disruptive to tone-elicited suppression than the tone had been to sucrose-elicited suppression. Additionally, the potential generalization decrement in the tone- trained groups may have reduced sensitivity in detecting reminder-induced recovery from the cue-toconsequence deficit. Experiment 6 eliminated these potential problems by testing all subjects with water rather than the sucrose solution; correspondingly, Group S was omitted. Instead, an explicitly unpaired tone/ $\mathrm{LiCl}$ group (EU) was included. As in Experiment 5 , tone presentation during conditioning and testing was contingent upon licking. However, on the test trial, the tone was presented beginning with the first lick rather than after 250 licks had been emitted, thereby eliminating another disparity between the treatment of the tone- $\mathrm{LiCl}$ and the sucrose$\mathrm{LiCl}$ groups in the previous experiments. Because water was present in the lick tubes on both Days 8 and 13, within-subject analyses of differences in latencies and volume consumed on these days was conducted in addition to the between-group analyses.

\section{Method}

Twenty-four naive male $(n=12)$ and female $(n=12)$ rats, approximately 74 days of age and ranging in weight from 203 to $343 \mathrm{~g}$, were used as subjects. Experimental groups were counterbalanced for sex. The source and maintenance of these animals were identical to those of Experiment 5 . The procedure was also the same as that of Experiment 5, with the following exceptions. Water was substituted for the sucrose solution in all stages of the study; Group S was replaced by Group EU, which received the lick-contingent tone and $\mathrm{LiCl}$ injection separated by $2 \mathrm{~h}$, as in Experiment 1; during testing the lick-contingent tone was available to each animal starting with the first lick of the session; and, with the tone being initiated starting with Lick 1 , the critical latency was now time to reach Lick 250.

\section{Results and Discussion}

Group mean log latencies to Lick 250 and Lick 500 as well as volumes consumed on Days 8 and 13 are presented in Table 6. No effect of sex on treatments was obtained; consequently, group means were collapsed across sex. No differences between groups were obtained for latencies or volume measures on Day 8 [Licks $0-250$ and Licks $250-500$, Fs $<1$; volumes, $F(3,18)=1.48, p>.10]$. ANOVAs found no significant differences between group means for Latencies $0-250$, Latencies 250-500, or volumes (all Fs $\leqslant 1.22$ ). In addition, a treatment $\times$ repeated measures ANOVA conducted on volumes of water consumed on Days 8 and 13 revealed no difference in 
Table 6

Mean Lick Training and Test Suppression Data From Experiment 6

\begin{tabular}{|c|c|c|c|c|c|c|c|c|c|c|c|c|}
\hline \multirow{2}{*}{ Group } & \multicolumn{6}{|c|}{ Day 8} & \multicolumn{6}{|c|}{ Day 13} \\
\hline & \multicolumn{2}{|c|}{$\begin{array}{c}\text { Latency* } \\
\text { Licks 0-250 }\end{array}$} & \multicolumn{2}{|c|}{$\begin{array}{c}\text { Latency* } \\
\text { Licks } 250-500 \\
\end{array}$} & \multicolumn{2}{|c|}{$\begin{array}{c}\text { Volume } \\
\text { Consumed** }\end{array}$} & \multicolumn{2}{|c|}{$\begin{array}{c}\text { Test Latency* } \\
\text { Licks } 0-250 \\
\end{array}$} & \multicolumn{2}{|c|}{$\begin{array}{l}\text { Test Latency* } \\
\text { Licks 250-500 }\end{array}$} & \multicolumn{2}{|c|}{$\begin{array}{l}\text { Test Volume } \\
\text { Consumed** }\end{array}$} \\
\hline NR & 1.74 & .04 & 1.88 & .07 & 18.05 & .80 & 1.76 & .03 & 1.88 & .12 & 18.05 & 1.55 \\
\hline TR & 1.76 & .03 & 2.01 & .20 & 15.58 & 1.13 & 1.74 & .06 & 1.74 & .04 & 17.67 & 1.04 \\
\hline LR & 1.74 & .03 & 1.90 & .09 & 18.24 & 1.41 & 1.70 & .05 & 1.76 & .02 & 19.72 & 1.60 \\
\hline
\end{tabular}

${ }^{*}$ In log sec \pm standard error. $\quad * * I n m l \pm$ standard error.

responding on these days $[F(1,18)=2.05, p>.10]$, no effect of treatment, and no interaction (Fs $<1)$. A similar analysis conducted on latencies to emit Licks $0-250$ on these days yielded no significant effects or interaction (all Fs $\leqslant 1.03$ ). A final withinsubject analysis of latencies to emit Licks $250-500$ on Days 8 and 13 found no main effects (Fs $\leqslant 1.29$ ) and no interaction $[F(3,17)=2.48, p>.05]$. Thus, even when the liquid presented during conditioning was the same as that used on the test trial, no suppression to the tone was observed with or without either of the reminder treatments. This suggests that the failures to detect suppression to the tone in Experiments 1-5 were not an artifact of stimulus generalization decrement between conditioning and testing.

\section{GENERAL DISCUSSION}

This series of experiments employed tone and $\mathrm{LiCl}$ reminder treatments across a variety of experimental parameters in an attempt to reveal latent tone- $\mathrm{LiCl}$ associations. Failure to reverse the cue-to-consequence deficit through reminder treatments in Experiments 1-6 suggests, to the extent that repeated null results can, that such deficits result from acquisition failure. Such a conclusion presumes that our procedures were sensitive to detecting retrieval failures. Several factors give credence to this assumption. First, the reminder procedures used in the present experiments have proven successful in reversing performance deficits following conditioning trials with footshock as the US (e.g., Balaz et al., 1982; Kasprow et al., 1982). Second, the $\mathrm{LiCl}$ injection employed in the present experiments yielded reliable manifest conditioning in sucrose- $\mathrm{LiCl}$ subjects, thereby demonstrating its adequacy as a US. Third, the tone has proved an adequate CS when paired with footshock (even weak shock) in prior experiments. Fourth, prior research suggests that conditioned suppression of drinking is a relatively sensitive response measure to assess conditioning of exteroceptive cues and internal malaise (Berk \& Miller, 1978). Fifth, cue-to-consequence deficits, that is, contraprepared associations, have been operationally defined as requiring a relatively large number of training trials to achieve observable associative strength (Seligman, 1970). Consequently, the use of a single conditioning trial in the present experiments maximized the difference in manifest suppression between the presumably prepared association (sucrose- $\mathrm{LiCl}$ ) and the presumably contraprepared association (tone- $\mathrm{LiCl}$ ), thereby enhancing the potential for manifest recovery of the contraprepared association.

In support of the present null finding, it should be noted that none of the experiments reported here found any tendency whatsoever towards suppression by tone-LiCl trained groups. The extremely low withingroup variabilities observed in the present experiments (see result sections for MSe) indicate a high sensitivity for detecting differences among tonetrained groups had these differences been present. These low variabilities within tone-trained groups occasionally resulted in $F$ ratios greater than unity, producing what might be interpreted as a nonsignificant tendency toward diferences between reminded and nonreminded subjects. However, such tendencies occurred as often in the direction of less suppression by reminded groups as in the direction of greater suppression by reminded groups.

On the basis of the present evidence, we tentatively conclude that cue-to-consequence deficits are attributable primarily to acquisition failure as opposed to retrieval failure. This is not to deny that nonconsummatory cues may play a significant role in modulating $\mathbf{~ L i C l - b a s e d ~ a s s o c i a t i o n s ~ w i t h ~ c o n s u m - ~}$ matory cues. A number of studies have demonstrated the influence of audiovisual cues on gustatory cuemalaise conditioning (e.g., Archer \& Sjödén, 1980; Domjan \& Best, 1980; Rudy, Rosenberg, \& Sandell, 1977). Despite these modulatory effects, neither the studies demonstrating them nor the present studies provide any evidence that cue-to-consequence deficits reflect retrieval failure. This of course is entirely consistent with both the initial and currently prevailing interpretation of cue-to-consequence effects, only now there is more of an empirical basis for this conclusion. Moreover, it is significant that cue-toconsequence deficits distinguish themselves from the 
many other associative performance deficits that have recently been found to stem from retrieval failures.

\section{REFERENCES}

Archer, T., \& Suödén, P.-O. (1980). Context-dependent tasteaversion learning with a familiar conditioning context. Physiological Psychology, 8, 40-46.

Archer, T., \& SJödÉn, P.O. (1982). Higher-order conditioning and sensory preconditioning of a taste aversion with an exteroceptive CS. Quarterly Journal of Experimental Psychology, 34B, 1-17.

Balaz, M. A., Gutsin, P., Cacheiro, H., \& Miller, R. R. (1982). Blocking as a retrieval failure: Reactivation of associations to blocked stimulus. Quarterly Journal of Experimental Psychology, 34B, 99-113.

Balaz, M. A., Kasprow, W. J., \& Miller, R. R. (1982). Blocking with a single compound trial. Animal Learning \& Behavior, 10, 271-276.

Berk, A. M., \& Miller, R. R. (1978). LiCl-induced aversions to audio visual cues as function of response measure and CS-US interval. Behavioral Biology, 24, 185-208.

Deweer, B., Sara, S. J., \& Hars, B. (1980). Contextual cues and memory retrieval in rats: Alleviation of forgetting by a pretest exposure to background stimuli. Animal Learning \& Behavior, 8, 265-272.

Domuan, M., \& Best, M. R. (1980). Interference with ingestional aversion learning produced by preexposure to the unconditioned stimulus: Associative and nonassociative aspects. Learning and Motivation, 11, 522-537.

Garcia, J., \& Koelling, R. A. (1966). Relation of cue to consequence in avoidance learning. Psychonomic Science, 4, 123-124.
KALAT, J. W. (1977). Status of "learned safety" or "learned noncorrelation" as a mechanism in taste-aversion learning. In L. M. Barker, M. R. Best, \& M. Domjan (Eds.), Learning mechanisms in food selection (pp. 273-293). Waco, TX: Baylor University Press.

Kasprow, W. J., Cacheiro, H., Balaz, M. A., \& Miller, R. R. (1982). Reminder-induced recovery of associations to an overshadowed stimulus. Learning and Motivation, 13, 155-166.

Kasprow, W. J., Catterson, D., Schachtman, T. R., \& Milder, R. R. (in press). Attenuation of latent inhibition by postacquisition reminder. Quarterly Journal of Experimental Psychology.

KRANE, R. V. (1980). Toxiphobia conditioning with exteroceptive cues. Animal Learning \& Behavior, 8, 513-523.

Miller, R. R., \& Springer, A. D. (1972). Induced recovery of memory in rats following electroconvulsive shock. Physiology \& Behavior, 8, 645-651.

Morrison, G. R., \& Collyer, R. (1974). Taste-mediated conditioned aversion to an exteroceptive stimulus following $\mathrm{LiCl}$ poisoning. Journal of Comparative and Physiological Psychology, 86, 51-55.

Riccio, D. C., \& Haroutunian, V. (1977). Failure to learn in a taste aversion paradigm: Associative or performance deficit? Bulletin of the Psychonomic Society, 10, 219-222.

Rudy, J. W., Rosenberg, L., \& Sandall, J. H. (1977). Disruption of a taste familiarity effect by novel exteroceptive stimulation. Journal of Experimental Psychology: Animal Behavior Processes, 3, 26-36.

Seligman, M.E. P. (1970). On the generality of the laws of learning. Psychological Review, 77, 406-418.

THORNDIKe, E. L. (1932). The fundamentals of learning. New York: Columbia University, Bureau of Publications.

(Manuscript received July 21, 1983; revision accepted for publication October 11, 1983.) 